\title{
A STUDY ON SAFETY ASPECTS IN STEEL INDUSTRIES
}

\author{
P. LAKSHMANA KUMAR ${ }^{\mathbf{1}} \boldsymbol{\&}$ P. SHANMUGHASUNDARAM ${ }^{\mathbf{2}}$ \\ ${ }^{1}$ Research Scholar, Department of Mechanical Engineering, Karpagam Academy of \\ Higher Education, Coimbatore, Tamil Nadu, India \\ ${ }^{2}$ Professor, Department of Automobile Engineering, Karpagam Academy of \\ Higher Education, Coimbatore, Tamil Nadu, India
}

\begin{abstract}
In India, the demand for steel immensely expanded since the turn of the thousand years because of the financial advancement. Iron and steel industries include an assortment of complex procedures and broad-scale tasks. The more significant part of the procedures is hazardous. The workplace of steel industries presents potential risks, and the workers are susceptible to high hazards. With a specific end goal to maintain a strategic distance from risks, appropriate and stringent precautionary procedures are to be adopted. A variety of working environment exercises or conditions in steel enterprises can cause accidents causing damage to property and risks prompting death, sickness or infections to the workers. The significance of safety management systems in limiting risks at steel industries in India is explained in this article.
\end{abstract}

KEYWORDS: Safety, Injury, Hazards \& Risk

Received: Jan 18, 2019; Accepted: Feb 08, 2019; Published: Mar 14, 2019; Paper Id.: IJMPERDAPR201951

\section{INTRODUCTION}

In high hazard enterprises such as steel industries, where workers work in locales with significant risks, there is constant risk of extreme injuries. Work-related injuries drive the organizations to suffer loss in various ways: lost profitability, money related loss owed to the expense of the damage, and loss of certainty from those specifically and in a roundabout way aggravated by the damage. For such reasons, organisations are intrigued to comprehend those variables that impact safety performance. For as far back as 30 years, the safety system executed to advance accident reduction has been embraced to investigate lagging presentations of safety performance. Lagging is a word used to portray the review idea of the factors connected to infer the measurements regularly utilised to survey safety performance. The disastrous component of applying lagging indicators, to be specific lost time accident rates and occurrence rates is that, someone effectively injured is viewed as valuable information. For the most part, safety metrics have expressed imperfections all the while (e. g. injuries), as an inverse to endeavoring to anticipate situations or conditions where damage is conceivable to happen. In the previous decade, loads of measures were taken with regard to occupational safety to perceive potential prescient strategies or leading indicators of safety performance (Manuele, 2009). The use of leading indicators is of view that, all together for the safety framework to be improved, disappointments in the system should initially occur. Nevertheless, safety climate and safety theory have been analysed by numerous researchers in an assorted variety of industrial settings; there has been a nonappearance of accord with regard to the meaning of the word safety climate and safety culture. One of the fundamental tools for recognising and surveying the overarching status of occupational safety and health 
management system in any industry is by receiving a safety audit system (Sivaprakash et al., 2013).

\section{SAFETY MANAGEMENT SYSTEM}

Last two decades has seen a few technological developments that have added to automatic, more dependable and cost-dynamic safety management methods and new types of equipment and systems. Receptiveness competence should be framed among the Indian Industry about tools and methodologies of safety methods to know and moderate the risks they are managing on an everyday premise, and make a protected workplace, for its very own machinery, workers and network around. The code of practice on safety management system will be exceptionally gainful for designing businesses, keeping in mind the end goal to prohibit risks and for giving a safe workplace to workers. The positive parts of Safe Workplaces are realised by numerous industries, and the reception of appropriate Safety Management Systems to stop hazardous occasions, maintain a strategic distance from worker accidents and different aftermaths related to mechanical accidents are expanding extensively. Safety management system additionally causes enterprises to upgrade worker learning of tasks, increment specific systems, keep up precise process safety data, and raise in general office profitability. Safety Management System is a word used to allude to an extensive business management framework planned to oversee occupational safety and safety fundamentals in the working environment. A Safety Management System offers an efficient method to distinguish risks and control risks while maintaining affirmation that these hazard controls are successful.

Safety Management System can be portrayed as a professional way to deal with safety. It is an efficient, express and thorough technique for overseeing risks. At the point when contrasted and other safety management systems, a safety management system clears approach to characterizing goal; objective situated arranging, executing, and assessing. Safety Management framework is a proactive and deliberate strategy for distinguishing proof, assessment, relief, anticipation and overseen risks that could happen because of disappointments in process, techniques, or equipment. Common accidents, death toll and property, open examination, statutory necessities, maturing offices and extraordinary mechanical procedures, all add to a developing requirement for Safety Management Program to affirm safety and hazard management. There are three necessities for embracing a safety management system for business - these are moral, lawful and budgetary.

\section{IRON AND STEEL PLANTS OF INDIA}

TATA Iron and Steel Company (TISCO) is one of the most seasoned iron and steel industries of India. It is a private sector enterprise, which at first had a capacity of creating 1.21 million tons of pig iron and 1.1 million tons of steel for every annum. The organisation changed its name from TISCO to Tata Steel in 2005. TATA Steel set an objective of accomplishing a yearly generation limit of 100 million tons by 2015. Indian Iron and Steel Company (IISCO) with three plants at Kulti, Hirapur and Bumpur in West Bengal were repaired in 1864, 1908 and 1937 individually. These plants have been consolidated and are known as the Indian Iron and Steel Company (IISCO). It was brought under government control and management in July 1972. IISCO was amalgamated with SAIL in 2006 and renamed IISCO Steel Plant.

Bhilai iron and steel Centre was built up in Durg region of Chhattisgarh in 1957 with the specialised and financial sustenance of the USSR. It was started in 1959. Its underlying limit was 10 lakh tons which have been raised to 52 lakh tons. New public sector organisation, the Bokaro Steel Ltd. was started in 1964 to erect a steel plant with the relationship of the erstwhile USSR at Bokaro close to the union of the Bokaro and Damodar streams in Hazaribagh region of Jharkhand. It was the second plant started with the Soviet help. It began generation in 1972. Its underlying capacity was 10 lakh tons which were raised to 40 lakh tons. 
The Salem Steel Plant was started at Salem in the Salem region of Tamil Nadu. The plant has the advantage of rich iron ore and limestone, which is quickly accessible in the adjacent zones. It additionally severs the offices of shoddy power, charcoal and huge market. The iron ore present here has low sulfur and phosphorus content and is fit for delivering unique review iron and steel. At present, the Salem Steel Plant is a primary maker of world-class treated steel and is in a situation to trade hardened steel to certain advanced nations, for example, the USA, Mexico, Australia and a few nations of South-East Asia.

Even though the steel process condition has seen a significant number of changes, the zone of safety still proceeds with significant risks. The available literature demonstrates numerous differences among the current steel enterprises' hazard factors, for example, damage rates, damage seriousness and other customarily utilised safety metrics. The steel industry, overall, has significantly enhanced safety performance and attempted to recognise those factors that impact and foresee safety performance, much the same as other high-risk enterprises (Flin et al., 2000). Having the capacity to utilize predictors of progress is much more attractive than recognising reasons for failures. Steel fabricating environments are regularly sorted by hazardous circumstances and conditions (Nordlof et al., 2015). Many survey articles provided details regarding recent injury, casualty and near miss reports in the steel manufacturing environment (Ibukun Awolusi and Eric Marks, 2015, Powlowska, 2015, Seyyed and Zahra, 2012).

In India, Steel plants have, for some time, been viewed as a standout amongst the most hazardous workplaces. The procedures involved in the generation of steel, in any of its structures, are inalienably dangerous and fit for causing handicap or death. More than 50 individuals die each year in major steel plants of the nation. What's more, very clearly, it is observed that the Indian steel industry has one of the most exceedingly terrible safety performances on the planet. The Green Rating Project (GRP) review has revealed that more than 144 individuals died in the period $2007-2010$ out of 17 of the 21 steel plants, which the survey considered. Poor occupational safety management system was found as a reasonable area of concern. While improvements have been made concerning safety performance, metal manufacturing as an industry has higher hazard than other general industries.

Even though there had been undeniable improvements in occupational safety in the steel industries, there remains a moderately high level of fluctuation in safety performance when looking at the different plants all over India. The industrial sector, in general, is walking toward more secure workplaces over the globe, and in particular, the steel industry has put in extraordinary efforts in enhancing safety performance and attempting to recognise those factors that impact safety performance. Industry groups such as the Indian Steel Organisation (ISA) have been instrumental in following injury rates, workers compensation costs and other metrics of safety performance, and following best practices that have positive results on safety-related conduct. What has turned out to be clear in a long while is that workplace safety has developed from an auxiliary issue to a working need with critical ramifications for task administrators. There is a development inside the steel business to utilise both driving and lagging indicators as measurements of progress for safety performance. Slacking markers are estimations, for example, OSHA recordable injury rates, days lost from work due to labor injury, and worker's compensation costs that think back to survey safety performance. Leading Indicators are pointers of safety performance, and cover such things as safety discussions among workers and the need to adopt improved safety measures under hazardous conditions. Driving pointers are factors that fundamentally anticipate hazardous conditions, and are by and large those that draw in workers and management, specifically in safety issues and this manner are seen as the more critical proportions of advancement (Robertson, 2008). 
The model proposed by Barling et al. (2002) represents the organisation between the transformational leader and the culture, which, it is proposed, impacts individual behaviour. Safety culture is an idea that is a culmination to corporate culture. Culture is an impression of shared practices, attitudes, and qualities concerning objectives. A safety society is said to be available when safety is perceived as the organization's best need. Weigmann et al. (2007) characterize safety culture as the continuing value and need imbibed by everybody in each gathering at each level of an organization. It alludes to the degree to which people and gatherings will focus on moral obligation regarding safety, act to save, upgrade and convey safety concerns, endeavor to effectively learn, adjust and alter (both individual and authoritative) conduct in view of exercises gained from missteps, and be compensated in a way reliable with these qualities. A positive safety culture is said to be intelligent about the relationship of a representative view of safety and the hierarchical pioneers' responsibility to safety. The literature till date exhibits that inside specific industries, the transformational pioneer positively affects the hierarchical attitudes concerning safety.

Attitudes may reflect culture and climate, however operationalizing these ideas into a generalisable worldview that can be connected comprehensively remains a test. The absence of an agreement about the meaning of the terms safety culture and safety climate makes it harder to show the apparent impact of authority on these factors. As agents attempt to associate extreme result estimations (e. g. injury rates and lost workdays) with the independent variable of management practices utilising safety climate or culture as an intermediary, the potential for error increments. A definitive trial of whether initiative practices affect safety performance can exhibit that, there is a factually noteworthy contrast in safety performance as estimated by limited and effectively characterised result estimations (e. g. injury rates and severity rates) between the different perceptible authority practices. Strikingly, this has not been assessed completely in the examination directed to date. What should be evaluated is, whether the transformational pioneer has an immediate effect on the result estimates that show the adequacy of safety programs. This is particularly valid concerning a high peril condition, for example, a steel process, where any successful prescient estimation could help to lessen accidents that cause injury or death.

\section{VARIOUS SAFETY MEASURES AGAINST HAZARDS}

There are several safety measure such as: Noise safety measures, Vibration safety measures, Chemical safety measures, Electrical safety measures, Gasses safety measures, Confined Space safety measures, safety measures while working at Heights, Work-to-Permit framework, Written conventions and so on. Unsafe acts and hazardous conditions are the significant causes leading to the accidents in the industry. Therefore, the safety reviews cover these two causes as real focuses.

The responsibility and duties of the workers related to safety management in the steel plant ought to be told. Reception of corrective measures after intensive examination of the past accidents both minor and major. There is a need to educate the steel plant workers concerning the safety occurrences, which have occurred in other steel industry, publicize the safety examination results among all the workers and direct consistent audit gatherings concerning the status of safety in the steel business. It is of utmost importance to boost safety-preparing programs for the workers including a discourse on the examination of different occurrences lead false crisis-management safety drills, direct consistent safety reviews to find hazardous regions and rehearse to guarantee that the remedial moves have been made.

Sentiment analysis, also known as opinion mining, is the analysis of the feelings that is people's opinions, sentiments, attitude, emotions, evaluations, appraisals towards entities such as products, services, organizations, 
individuals, issues, events, topics, and their attributes using natural language processing tools. This can be effectively used for workplace safety (Chitra et al, 2017)

The safety audits are led inside and remotely by the qualified and skillful workers. Inside reviews of Occupational Health and Safety Management Systems are done in every one of the territories, to decide if the OHSMS is viably actualised and kept up according to the measures of OHSAS 18001:2007.

\section{CONCLUSIONS}

A steel industry, which is of hazardous nature, should give concern to the safety of workers, equipment and the environment. Safety of workers ought to be given primary significance, since it influences both financial and social factors. It is the chief obligation of the best management of any steel plant to give safe workplace to its workers by actualising safety management systems. The act of safety management systems gives favorable circumstances such as aversion of dangerous occasions, maintenance of a strategic distance from generation and labor accident and fallouts related to the accidents. Upgrade of workers learning of operation, change of specialised methodology, support of accurate processsafety data and increment in plant productivity are the extra advantages determined by safety management systems.

\section{REFERENCES}

1. Manuele, F., (2009). Leading and lagging indicators. Professional Safety, 54 (12), 28-33.

2. Sivaprakash P, Elangovan RK, Karthikeyan LM, Sebastian joseph, (2013). A Study on Safety Audit System in Indian Engineering Industries, Life Science Journal, Vol.10, No. 9s, pp.236-240.

3. Flin, R., Mearns, K., O'Connor, P., \&Bryden, R. (2000). Measuring safety climate: Identifying the common features. Safety Science, 34, 177-192.

4. Hasse Nordlof, Birgitta Wiitavaara, Ulrika Winblad, Katarina Wijk, Ragnar Westerling,(2015). Safety culture and reasons for risk-taking at a large steel- manufacturing company: Investigating the worker perspective. Safety Science, 73, 126-135.

5. KHAN, M. Z. H. (2017). A case study on Occupational health and safety of footwear manufacturing industry. Journal of Business and General Management, 2, 1-6.

6. Zofia Pawtowska, (2015). Using lagging and leading indicators for the evaluation of occupational safety and health performance in industry. International Journal of Occupational Safety and Ergonomics, 21(3), 284-290.

7. Seyyed Shahab Hosseinian, Zahra Jabbarani Torghabeh, (2012). Major Theories of Construction Accident Causation Models: A Literature Review, International Journal of Advances in Engineering \& Technology. 4(2), 53-66.

8. Ibukun Awolusi\& Eric Marks, (2015). Near-Miss Reporting to Enhance Safety in the Steel Industry, Iron \& Steel Technology, $62-68$.

9. Nwigbo S. C, Nzemeke K. E, Mbachu V. M, (2016). Factory Accidents Survey and Performance Evaluation in A Nigerian Steel Rolling Mills, International Journal of Engineering and Technical Research, 6(4), 41 - 45.

10. Bathrinath, S., Devaganesh, J., Santhi, B., \& Saravanasankar, S. The Adverse Human Health Effects Due To Ammonia, Hydrogen Sulphide And Chlorine In Process Industry: A Review.

11. Robertson, S. (2008). Is steel's safety net fraying? American Metal Market, 117(4), 52-54.

12. Barling, J., Loughlin, C., \& Kelloway, E. K. (2002). Development and test of a model linking transformational leadership and occupational safety. Journal of Applied Psychology, 87, 488-496. 
13. Wiegmann, D., Von Thaden, $T$ \& Gibbons, A. (2007). A review of safety culture theory and its potential application to traffic safety. In improving traffic safety culture in the United States: The journey forward, 113-129.

14. K. Chitra, T. Kavitha, S. Hemalatha, A Survey on Opinion Mining: Techniques, Tools and Research Challenges in Sentiment Analysis, Research Journal of Science and Engineering Systems, Vol.1, pp.43-51,2017. 